\title{
Optimal management of genital herpes: current perspectives
}

This article was published in the following Dove Press journal:

Infection and Drug Resistance

13 June 2016

Number of times this article has been viewed

\begin{abstract}
Andreas Sauerbrei
Institute of Virology and Antiviral Therapy, German Consulting Laboratory for Herpes Simplex Virus and Varicella-Zoster Virus, Jena University Hospital, Friedrich-Schiller University of Jena, Jena, Germany
\end{abstract}

\begin{abstract}
As one of the most common sexually transmitted diseases, genital herpes is a global medical problem with significant physical and psychological morbidity. Genital herpes is caused by herpes simplex virus type 1 or type 2 and can manifest as primary and/or recurrent infection. This manuscript provides an overview about the fundamental knowledge on the virus, its epidemiology, and infection. Furthermore, the current possibilities of antiviral therapeutic interventions and laboratory diagnosis of genital herpes as well as the present situation and perspectives for the treatment by novel antivirals and prevention of disease by vaccination are presented. Since the medical management of patients with genital herpes simplex virus infection is often unsatisfactory, this review aims at all physicians and health professionals who are involved in the care of patients with genital herpes. The information provided would help to improve the counseling of affected patients and to optimize the diagnosis, treatment, and prevention of this particular disease.
\end{abstract}

Keywords: herpes simplex virus, epidemiology, infection, antiviral therapy, laboratory diagnosis, prevention

\section{Herpes simplex virus}

Herpes simplex virus type 1 (HSV-1) and type 2 (HSV-2) are classified within the genus Simplexvirus that belongs to the subfamily Alphaherpesvirinae within the family Herpesviridae. Both are neurotropic DNA viruses with an envelope, have a size of 150-200 nm, and are characterized by low environmental resistance. ${ }^{1}$ An electron micrograph in Figure 1 shows the composition of herpes simplex virus (HSV) which is comparable for both types. The viral double-stranded DNA genome with a length of $152 \mathrm{~kb}$ encodes at least 84 different structural and nonstructural proteins. ${ }^{2}$ The viral protein capsid comprises 162 capsomers and has an icosahedral structure. Viral genome and capsid are summarized under the term nucleocapsid. The surrounding lipid envelope consists of host cell components and virus-encoded glycoproteins. Between nucleocapsid and outer envelope, a protein layer referred to as tegument is situated. The replication of herpesviruses is a complex process characterized by the cascade-like sequential expression of $\alpha, \beta$, and $\gamma$ genes. $^{3}$ This process mainly takes place within the nucleus of the infected host cells. The sequence homology between the genome of HSV-1 and HSV-2 is $\sim 40 \%$, leading to nearly $85 \%$ homology of gene regions encoding virus-specific proteins. Thus, both viruses are biologically similar, and their antigens show high cross-reactivity. Type-specific epitopes are present on the surface glycoproteins gG (HSV-1 and HSV-2) ${ }^{4}$ and gC (HSV-1). ${ }^{5}$
Correspondence: Andreas Sauerb

Therapy, Jena University Hospital, Friedrich-Schiller University of Jena, Hans-Knoell-Strasse 2, 07745 Jena, Germany

$\mathrm{Tel}+49364 \mid 9395700$

Fax +49 364I 9395702

Email Andreas.Sauerbrei@med.uni-jena.de 


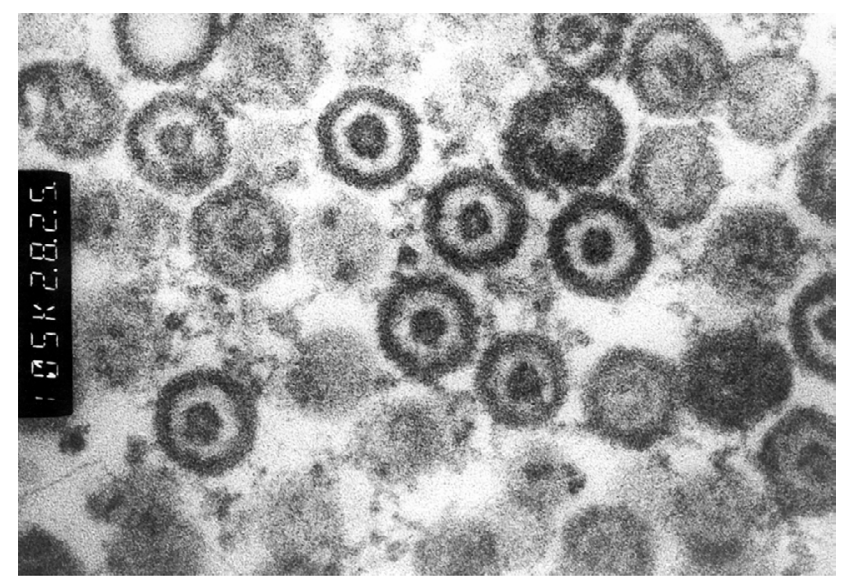

Figure I Electron micrograph of HSV-I $(\times \mid 05,000)$ showing the composition of the virus: nucleocapsid with high density surrounded by the tegument with low density and the envelope with high density.

Note: Courtesy of the Institute of Virology and Antiviral Therapy, Jena University Hospital, Friedrich-Schiller University of Jena, Germany.

Abbreviation: HSV-I, herpes simplex virus type I.

\section{Epidemiology}

\section{Virus transmission and seroepidemiology}

HSV-1 and HSV-2 are mainly transmitted by direct contact. ${ }^{6}$

The viruses are mostly acquired from symptomatic people with recurrent infections mainly at the lips or genitals or from asymptomatic persons shedding the virus through saliva and genitals. ${ }^{6} \mathrm{HSV}-1$ infections predominantly affect the body above the waist, and HSV-2 infections are dominant below the waist. After disappearance of protective maternal antibodies during the first year of life, the frequency of primary HSV-1 infections occurring mostly during infancy and childhood varies as a function of the socioeconomic status. ${ }^{7}$ Current seroprevalence data from Germany reveal an increase of antiHSV- 1 IgG from $19 \%$ by the age of $2-3$ years, to $57 \%$ among 10 - to 12 -year-olds, to $69 \%$ by the age of $16-18$ years, and to $78 \%$ among 28 - to 30 -year-olds. ${ }^{8}$ In European countries, HSV-1 seroprevalence varies in adults from $50 \%$ to $\geq 85 \%$ during the last 2 decades. ${ }^{7,9}$

HSV-2 is predominantly transmitted by sexual contact ${ }^{7}$ and has to be considered the major cause of genital herpes. ${ }^{10}$ Thus, the overwhelming majority of HSV-2 primary infection is acquired with starting sexual intercourse after puberty, and in contrast to HSV-1, HSV-2 infections are mainly diagnosed in adolescents and adults. As previously shown for Germany, HSV-2 seroprevalence increases from $\sim 3 \%$ in children aged $10-15$ years to $7 \%$ among 16 - to 18 -year-olds and to $14 \%$ among adults. ${ }^{8}$ Overall, HSV-2 seroprevalence rates depend on the age, sex, number of lifetime sexual partners, and socioeconomic status. ${ }^{7,9}$ Seroprevalences above the levels of the general population have been found in high-risk sexual behaviors and HIV-positive people as well as in homosexual men. ${ }^{7}$ Several studies found significantly higher prevalence of anti-HSV-2 IgG among women than men., ${ }^{8,911,12}$ It has been discussed as a possible reason that men tend in principle to develop more asymptomatic genital HSV-2 infections than women, leading to higher rates of viral transmission from men to women. ${ }^{11}$ By contrast, infected women have a higher proportion of symptomatic genital herpes promoting them to abstain from sexual intercourse. Because of the high antigenic cross-reactivity between HSV-1 and HSV-2, people with past primary HSV-1 infection probably have a lower risk of acquiring HSV-2 and vice versa. ${ }^{13}$ It is known that HSV-2 genital infections may increase the risk of acquiring HIV infection. ${ }^{14}$

\section{Changes in seroepidemiology}

During the past few decades, there have been changes especially in seroepidemiology of HSV-1. In the US, the overall HSV-1 seroprevalence decreased, in particular among children, between the 1980s and 2000s.$^{15}$ In Germany, a reduced prevalence of HSV-1 antibody among children and adolescents has been found, ${ }^{8}$ and a substantial reduction of HSV-1 seroprevalence has recently been reported among Finnish children. ${ }^{16}$ The consequences may be a higher number of primary HSV-2 infections and/or a higher proportion of genital diseases caused by HSV-1 primary infections through oral sex among adolescents and adults. Indeed, there has been evidence that the number of genital herpes diseases due to HSV-1 primary infections has increased among young people, especially in the US..$^{10,17}$ However, HSV-1 is less likely to lead to recurrences in the genital tract than HSV-2. ${ }^{18}$

\section{Infection}

HSV enters the body during primary infection through lesions of mucous membranes and skin and replicates locally in the keratinocytes of skin, epithelial cells of mucous membranes, and regional lymph nodes. It may follow a short viremia that is difficult to diagnose. ${ }^{19}$ After an incubation period of $2-12$ days, ${ }^{20}$ only $1 \%$ of infected people are at risk of developing diseases mostly characterized by typical herpes blisters at the site of virus entry, and the overwhelming majority, $99 \%$ of the infected people, show a clinically unapparent course. ${ }^{21,22}$ For HSV-2, the majority of primary infections are also asymptomatic. ${ }^{11}$ After the onset of primary infection, both HSV-1 and HSV-2 migrate via retrograde axonal transport to sensory nerve ganglions where they establish latency, and the circular viral DNA persists in neurons..$^{23}$ The type of ganglia in which the viruses establish latency is dependent upon the ganglia associated with the 
nerves innervating the site of infection. Thus, HSV-1 mostly remains latently in the trigeminal ganglion and HSV-2 in sacral ganglia. From there, viruses may be reactivated, and after neural anterograde transport, they may cause recurrent infections, especially of skin and mucous membranes. ${ }^{22}$ Recurrent infections, caused by HSV-1 or HSV-2 may occur in up to $40 \%$ of the latently infected individuals, but immunodeficient people are more frequently and especially more severely affected..$^{21}$ Subclinical reactivations of HSV-1 or HSV-2 associated with asymptomatic shedding occur frequently ${ }^{24,25}$ and may help to boost the immune system. Clinically manifested recurrent infections caused by endogenous virus reactivation occur frequently after puberty in the case of immunogenetic predisposition, but their prevalence drops with age. ${ }^{22}$ It is known that virus reactivation can be triggered by multiple environmental and physiological factors such as fever, ultraviolet light, and trauma. ${ }^{26,27}$

Even though there is extensive information on HSV biology, the absolute mechanism of HSV latency and endogenous virus reactivation is currently unknown. In human ganglia, HSV genomic DNA persists in a nonintegrated form, most likely as circular episome. ${ }^{28}$ The latency-associated transcripts expressed by the virus seem to be of crucial significance for latency, since the most abundantly detected viral RNAs in latently infected ganglia originate from latency-associated transcripts and lytic regions are silent. ${ }^{29}$ The HSV-1 reactivation has been hypothesized as a three-step epigenetically regulated process: 1) animation of latent virus genome by reactivation stimuli followed by generalized transcription of viral genes, 2) exit from latency with the classical three-step transcription of $\alpha, \beta$, and $\gamma$ genes, critically dependent on the function of HSV-1 VP1, and 3) production and release of infectious virus. ${ }^{30}$

\section{Genital herpes disease Common diseases}

An overview of different HSV-1 and HSV-2 diseases is given in Figure 2. The most common symptomatic HSV infections, irrespective of primary or recurrent infections, are localized on skin and mucous membranes such as herpetic gingivostomatitis (HSV-1), herpetic keratoconjunctivitis (HSV-1), herpes labialis or facialis (HSV-1), eczema herpeticum (HSV-1, rarely HSV-2), and herpes genitalis (HSV-2, rarely as a recurrent HSV-1 infection). In general, HSV has been considered the most common cause of sexually transmitted infections leading to ulcers. ${ }^{31}$ Genital disease caused by HSV-2 is clinically indistinguishable from that caused by HSV-1. Infections of the central nervous system (CNS) and the sense organs may manifest as encephalitis, meningitis, myelitis, or retinitis (HSV-1, HSV-2), and in immunocompromised patients, disseminated infections with visceral manifestations of the lungs, liver, or esophagus (HSV-1, HSV-2) may occur. Additionally, neonatal or congenital (very rarely) herpes (HSV-2, HSV-1) results from perinatal or prenatal (intrauterine) infection among pregnant women or neonates. ${ }^{19}$

\section{Primary genital herpes}

Primary genital infections caused by HSV-1 or HSV-2 are mostly not associated with clinical symptoms and remain asymptomatic. ${ }^{32}$ In addition, atypical clinical presentations may occur. The classic clinical picture of primary genital herpes is characterized by typical lesions of mucous membranes appearing as maculae and papules, followed by vesicles, pustules, and ulcers. These lesions usually arise within 4-7 days after sexual exposure and last up to 3 weeks. ${ }^{33}$ Lesions are mostly presented on the external genitalia characterized by bilateral clusters, but they can also be localized in the perianal region, on the buttocks, or upper thighs. ${ }^{34}$ The typical patient's symptoms are pain, itching, burning, and dysuria. In primary infection, the genital lesions may be accompanied by lymphadenopathy, fever, cervicitis (women), and proctitis (homosexual men). The disease is often more severe in women than in men, also with regard to the prevalence of complications, including aseptic meningitis and urinary retention. Several authors differentiate between "initial primary" and "initial nonprimary" genital infection. While initial primary infection means the first virus exposure in anti-HSV-1/2 IgG-negative persons, initial nonprimary infection is defined as first HSV-1 or HSV-2 infection in persons having IgG antibodies against the other virus type than the one causing acute infection. Due to cross-reaction of HSV-1 and HSV-2 antibodies, initial nonprimary genital infections cause milder symptoms than initial primary infections.

\section{Recurrent genital herpes and asymptomatic viral shedding}

Reactivation of latent HSV can result in symptomatic recurrent episodes of genital herpes, called as recurrences, or in asymptomatic viral shedding. In general, almost all persons with symptomatic primary HSV-2 infection of the genital tract also have recurrences, and more than one-third have frequent recurrences. ${ }^{35}$ By contrast, genital HSV-1 recurs infrequently. The genital HSV-1 recurrence rate is $\sim 20 \%$ of the rate described for genital HSV-2 in the first year of 


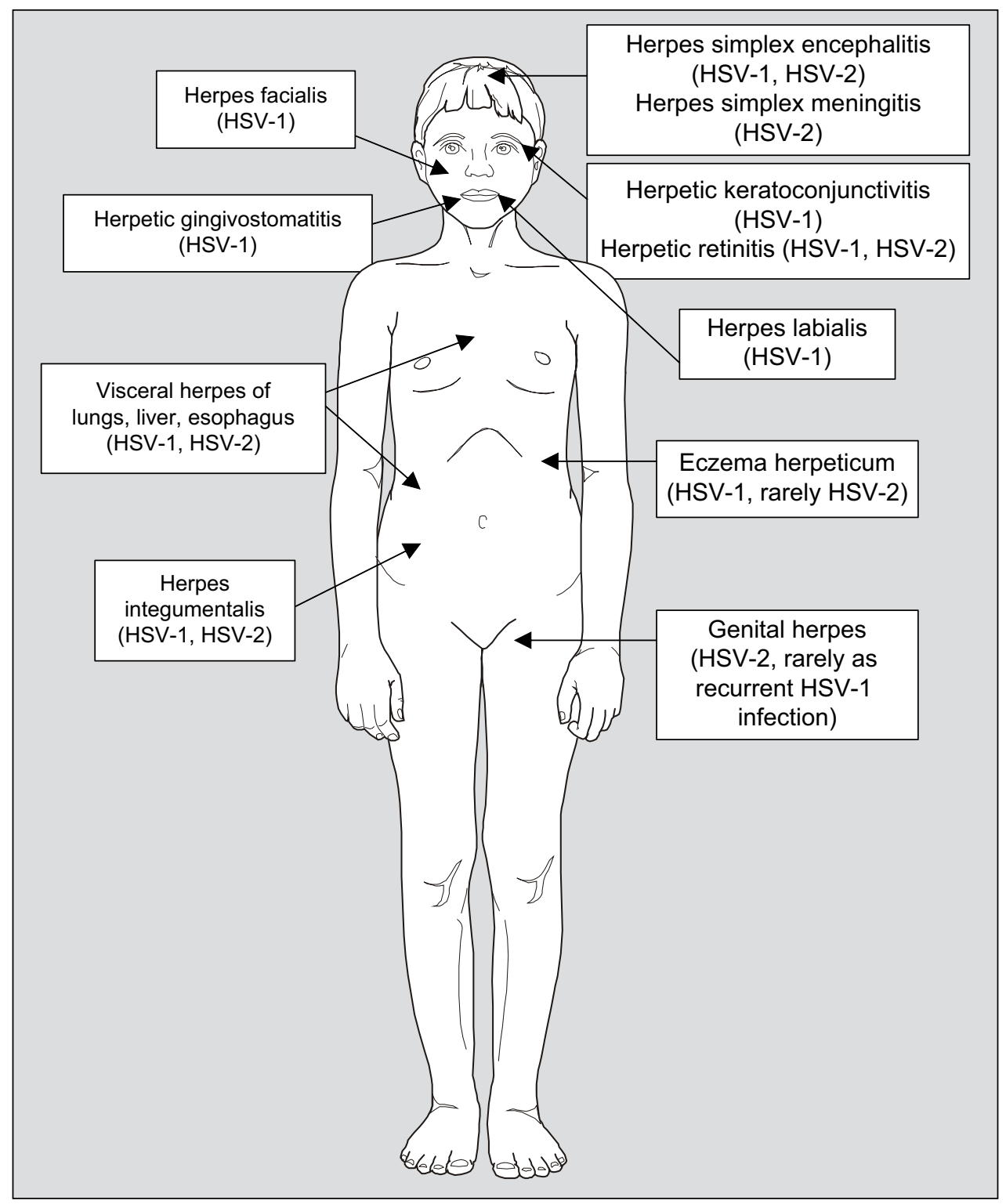

Figure 2 Different HSV-I and HSV-2 diseases and their localization.

Abbreviations: HSV-I, herpes simplex virus type I; HSV-2, herpes simplex virus type 2.

infection, and there is a considerably more rapid decrease over time for HSV-1 than for HSV-2. ${ }^{36}$ As the earliest signs of recurrent episodes, prodromal symptoms may occur presenting as paresthesia and pains in the area of lumbosacral dermatomes ${ }^{34}$ In comparison to primary infection, recurrent genital herpes appears as a less severe disease with a shorter duration. ${ }^{33}$ Usually, men have a small number of vesicles, and female infection is associated with genital lesions appearing as vesicles and ulcers or merely causes vulvar irritation lasting $\sim 8-10$ days..$^{20} \mathrm{~A}$ third of patients have been reported to have more than six recurrences per year. ${ }^{20}$ According to experiences obtained from the consulting activities of the German Consulting Laboratory for Herpes Simplex Virus and Varicella-Zoster Virus (Institute of Virology and Antiviral Therapy, Jena University Hospital, Jena, Germany), especially young women, exposed to severe psychosocial stresses in work and family, are affected by recurrent genital herpes disease. It is important not to neglect that distinct recurrent genital herpes is often associated with significant psychosocial disturbances in the affected individuals and their sexual partners. ${ }^{37}$

Asymptomatic genital shedding without clinical symptoms is most frequent in HSV-2-seropositive individuals. Studies have shown that nearly $90 \%$ of these persons have shedding episodes over time, while HSV-1 shedding has only been reported in rare cases. ${ }^{38}$ 


\section{Virus transmission}

During genital herpes or asymptomatic viral shedding, HSV can be transmitted to sexual partners. Both primary and recurrent maternal infection during pregnancy can lead by intrauterine virus transmission to congenital disease, a rare disorder amounting to $\sim 5 \%$ of all infections caused by HSV in neonates. ${ }^{39}$ The danger of intrauterine viral transmission is highest after primary HSV-2 infection and during the first 20 gestational weeks. The fetal infection may result in abortion, stillbirth, or congenital disease, which is normally accompanied by skin lesions and eye and neurological damages. ${ }^{40}$ Exposure to HSV in the genital tract at the time of delivery is regarded as the main reason of neonatal HSV infections, of which $70 \%-85 \%$ are caused by HSV- $2 .{ }^{41}$ In the US, the incidence ranges from 5 to 31 per 100,000 live births, and the prognosis is poorer in neonatal HSV-2 infections than that related to HSV- $1 .{ }^{39}$ The highest risk of neonatal infection has been estimated in neonates born from mothers with primary HSV infection near term, but most neonatal infections arise from virus exposure through asymptomatic viral shedding via the genital tract near delivery. ${ }^{39,42}$ The clinical manifestations of neonatal HSV infections are categorized into three major groups of infections: (i) localized to skin, eye, and mucous membranes, (ii) CNS, and (iii) disseminated systemic. ${ }^{43}$

\section{Laboratory diagnosis Virus detection}

HSV-1 and HSV-2 can be detected in lesions of skin and mucous membranes in patients with acute genital herpes infections or in the absence of active lesions from genital mucous membranes to verify asymptomatic viral shedding. In the presence of mucocutaneous lesions, the collection of vesicular fluid by swabbing is the method of choice. The vesicle content or swab has to be placed into vials containing physiological saline or viral transport medium. HSV-positive samples have to be shipped as dangerous goods category B and risk group 2 in accordance with the UN 3373 regulations. ${ }^{44}$ The patient's sample within a primary container has to be placed within an outer packaging containing adsorbing material, and the transportation should be carried out in a cardboard box. Shipment is recommended at room temperature unless samples have to be used for isolation of HSV in cell culture. ${ }^{44}$ In this case, cooling is required, since the infectivity of HSV is highly dependent on temperature, humidity, and $\mathrm{pH}$ value. ${ }^{45}$

Acute genital HSV infections are diagnosed (Table 1) by laboratory detection of DNA of HSV-1 and HSV-2 by means of polymerase chain reaction (PCR) ${ }^{46}$ In case of complications or the involvement of other organs, cerebrospinal fluid, tissue, bronchoalveolar lavage, ethylenediaminetetraacetic acid blood, serum, amniotic fluid, or intraocular fluid can be used as specimens. The PCR method should be used to discriminate between both HSV-1 and HSV-2. ${ }^{47}$ Many laboratories use qualitative or quantitative in-house PCR assays, but commercial test kits are also available. ${ }^{45}$ Alternatively, the acute genital HSV infection or asymptomatic shedding can be diagnosed by viral isolation in cell culture. It is appropriate to type the virus isolates by means of immunofluorescence using HSV serotype-specific fluorescein-labeled monoclonal antibodies. In general, the viral culture has been accepted as a sensitive method for detection of HSV, since both HSV-1 and HSV-2 replicate well in many cell types such as human embryonic fibroblasts, Vero, or HEp-2 cells. However, because of the higher sensitivity, ${ }^{48}$ the PCR technique is currently accepted as gold standard in many laboratories. Recently, the Centers for Disease Control and Prevention stated that the "specific evaluation of genital, anal, or perianal ulcers includes culture or PCR testing for genital herpes". ${ }^{49}$ Furthermore, the direct detection of HSV antigens

Table I Methods for detection of HSV including viral nucleic acid (DNA)

\begin{tabular}{|c|c|c|c|}
\hline Principle & Method & Patient samples & Remarks \\
\hline $\begin{array}{l}\text { Detection of } \\
\text { viral DNA }\end{array}$ & Polymerase chain reaction & $\begin{array}{l}\text { Vesicle content/swab, in I mL physiological saline or viral transport } \\
\text { medium } \\
\text { Cerebrospinal fluid, tissue, bronchoalveolar lavage, EDTA blood, } \\
\text { amniotic fluid, intraocular fluid }\end{array}$ & Basic diagnostics \\
\hline Viral isolation & $\begin{array}{l}\text { Viral growth in cell } \\
\text { culture, detection by } \\
\text { monoclonal antibody }\end{array}$ & $\begin{array}{l}\text { Vesicle content in viral transport medium with special swab, tissue, } \\
\text { bronchoalveolar lavage } \\
\text { Transport under cooling }\left(2^{\circ} \mathrm{C}-8^{\circ} \mathrm{C}\right)\end{array}$ & Special diagnostics \\
\hline Virus detection & $\begin{array}{l}\text { Immunofluorescence test } \\
\text { using monoclonal antibody }\end{array}$ & $\begin{array}{l}\text { Cell-rich vesicle content in viral transport medium with special swab, } \\
\text { tissue }\end{array}$ & $\begin{array}{l}\text { Basic diagnostics } \\
\text { Reduced sensitivity and specificity }\end{array}$ \\
\hline Virus typing & $\begin{array}{l}\text { Immunofluorescence test } \\
\text { using monoclonal antibody }\end{array}$ & Virus isolate & Basic diagnostics \\
\hline
\end{tabular}

Abbreviations: HSV, herpes simplex virus; EDTA, ethylenediaminetetraacetic acid. 
by means of commercial detection systems on the basis of immunofluorescence or enzyme-linked immunosorbent assay (ELISA) is a frequently used and cost-effective assay. This technique provides results within a few hours, but it lacks sensitivity and specificity. ${ }^{31,50}$ It has to be taken into account that laboratory methods, which diagnose HSV-1 or HSV-2 infection by viral growth, detection of DNA, or viral antigens, do not distinguish between primary HSV infection, recurrent HSV infections, and HSV shedding.

\section{Determination of antibodies}

HSV serological methods are widely used for the indirect laboratory diagnosis of infections caused by HSV-1 or HSV-2. Serological methods (Table 2) are especially important for the diagnosis of primary HSV infection when seroconversion of virus-specific IgG antibodies can be observed. The detection of IgG seroconversion can also be performed by the use of HSV type-specific antibody assays. Because of the close relationship between HSV-1 and HSV-2, the determination of type-specific IgG is only possible by the use of ELISA or immunoblot on the basis of glycoproteins $\mathrm{G}$ (gG-1) or $\mathrm{C}$ ( $\mathrm{gC}-1$ ) of HSV-1 and the glycoprotein G (gG-2) of HSV-2., For the interpretation of results, one has to bear in mind that there is a partial cross-immunity between HSV-1 and HSV-2. HSV type-specific IgG assays are potentially useful

Table 2 Different methods used for detection of HSV-specific antibodies

\begin{tabular}{ll}
\hline Method & Remarks \\
\hline Ligand assays & Determination and differentiation of \\
(ELISA, & immunoglobulin (Ig) classes (IgG, IgM) in serum, \\
chemiluminescence & plasma, and cerebrospinal fluid \\
immune assay, etc) & Determination of type-specific antibodies to viral \\
& glycoproteins (gG-I, gC-I, gG-2) \\
& Determination of type-common antibodies using \\
& whole viral antigen from cell cultures infected with \\
& HSV-I or HSV-2 \\
& Simple handling, distributed commercially, \\
& automated, basic diagnostics \\
& Determination and differentiation of Ig classes \\
(lgG, IgM) in serum, plasma, and cerebrospinal fluid \\
Indirect & Simple handling, distributed commercially, requires \\
fluorescence & experience in microscopic evaluation, special \\
antibody test & diagnostics \\
Qualitative determination of type-specific lgG & antibodies to viral glycoproteins (gGI, gG2) in serum \\
Simple handling, sensitive, distributed \\
assay
\end{tabular}

Abbreviations: HSV, herpes simplex virus; ELISA, enzyme-linked immunosorbent assay; HSV-I, HSV type I; HSV-2, HSV type 2. to identify HSV carriers, in particular of HSV-2. ${ }^{51,52}$ The presence of anti-HSV-2 IgG implies most likely anogenital infection and high probability of asymptomatic viral shedding. HSV type-specific serological tests have been available commercially for $>1$ decade, and there is a strong consensus that assays on the basis of $\mathrm{gG}-1$ and $\mathrm{gG}-2$ are most accurate for discrimination of past (latent) HSV-1 from past (latent) HSV-2 infection. It should be, however, considered that the specificity can be reduced in populations with a high prevalence of diseases caused by HIV. ${ }^{53}$ If a first serum sample from the early phase of disease is available, the detection of HSV-1 and HSV-2 DNA using type-specific PCR in combination with the type-specific detection of anti-HSV-1 and anti-HSV-2 IgG may permit a distinction between primary and recurrent HSV-1 or HSV-2 infection. ${ }^{54}$ That means, for example, when HSV-2 is detected in genital lesions of pregnant women some weeks before delivery, primary herpes can be distinguished from recurrent genital herpes using type-specific HSV serology. A negative anti-HSV-1 or antiHSV-2 IgG excludes recurrent HSV-1 or HSV-2 infections. Despite the advantages of HSV type-specific serology, many laboratories do not offer these assays but provide only typecommon serologic tests. ${ }^{55,56}$ Table 3 provides a summary of virological and serological data for the laboratory diagnosis of HSV infection with and without genital herpes lesions and asymptomatic viral shedding.

Determination of anti-HSV-1 or anti-HSV-2 IgG avidity may also allow the differentiation between primary and recurrent HSV-1 or HSV-2 infections, but there is only very limited experience in this including the diagnosis of genital herpes. ${ }^{57}$ Intrathecal HSV antibodies may be of value for the retrospective laboratory diagnosis of CNS infections caused by HSV. ${ }^{58}$ Anti-HSV IgM is only of minor significance for the early diagnosis of acute HSV infection. Due to cross-reactions to other herpesviruses, especially the varicella-zoster virus, IgM assays may show false-positive results. Only type-common HSV IgM ELISAs with high sensitivity and specificity may be useful to confirm acute HSV infections. ${ }^{59}$ This can apply to IgM as a marker for newly acquired genital HSV infections especially caused by HSV-2 ${ }^{60}$ and may be of significance in particular in the management of pregnant women. However, IgM results appear to be ineffective at discriminating early (primary) from established infections, ${ }^{61}$ and the positive predictive value of HSV IgM assays for acute HSV infection is low. A further drawback is that the determination of IgM antibodies has practically no significance for the timely diagnosis of acute primary and recurrent HSV infection. The use of HSV type-specific IgM ELISAs, which are offered 
Table 3 Laboratory data for diagnosis of HSV infection dependent on genital herpes lesions

\begin{tabular}{|c|c|c|c|c|c|c|}
\hline \multirow{2}{*}{$\begin{array}{l}\text { Clinical } \\
\text { signs }\end{array}$} & \multicolumn{3}{|l|}{ HSV serology } & \multicolumn{2}{|l|}{ PCR } & \multirow[t]{2}{*}{ Interpretation/status of infection } \\
\hline & HSV-I/2 IgG & HSV-I IgG & HSV-2 IgG & HSV-I & HSV-2 & \\
\hline \multirow{4}{*}{$\begin{array}{l}\text { Primary } \\
\text { genital } \\
\text { herpes }\end{array}$} & Neg & Neg & Neg & Pos & Neg & Acute HSV-I infection \\
\hline & Pos & Neg & Pos & Pos & Neg & Acute HSV-I infection, HSV-2 latency \\
\hline & Neg & Neg & Neg & Neg & Pos & Acute HSV-2 infection \\
\hline & Pos & Pos & Neg & Neg & Pos & Acute HSV-2 infection, HSV-I latency \\
\hline Recurrent & Pos & Pos & Neg & Pos & Neg & Recurrent HSV-I infection \\
\hline genital & Pos & Pos & Pos & Pos & Neg & Recurrent HSV-I infection, HSV-2 latency \\
\hline \multirow[t]{2}{*}{ herpes } & Pos & Neg & Pos & Neg & Pos & Recurrent HSV-2 infection \\
\hline & Pos & Pos & Pos & Neg & Pos & Recurrent HSV-2 infection, HSV-I latency \\
\hline No genital & Neg & Neg & Neg & Neg & Neg & Susceptibility \\
\hline herpes & Pos & Pos & Neg & Neg & Neg & Past HSV-I infection (HSV-I latency) \\
\hline \multirow[t]{6}{*}{ lesions } & Pos & Neg & Pos & Neg & Neg & Past HSV-2 infection (HSV-2 latency) \\
\hline & Pos & Pos & Pos & Neg & Neg & Past HSV-I and HSV-2 infection (HSV-I and HSV-2 latency) \\
\hline & Pos & Pos & Neg & Pos & Neg & $\begin{array}{l}\text { Asymptomatic shedding of HSV-I, past HSV-I infection (HSV-I } \\
\text { latency) }\end{array}$ \\
\hline & Pos & $\mathrm{Neg}$ & Pos & $\mathrm{Neg}$ & Pos & $\begin{array}{l}\text { Asymptomatic shedding of HSV-2, past HSV-2 infection (HSV-2 } \\
\text { latency) }\end{array}$ \\
\hline & Pos & Pos & Pos & Pos & Neg & $\begin{array}{l}\text { Asymptomatic shedding of HSV-I, past HSV-I and HSV-2 infection } \\
\text { (HSV-I and HSV-2 latency) }\end{array}$ \\
\hline & Pos & Pos & Pos & $\mathrm{Neg}$ & Pos & $\begin{array}{l}\text { Asymptomatic shedding of HSV-2, past HSV-I and HSV-2 infection } \\
\text { (HSV-I and HSV-2 latency) }\end{array}$ \\
\hline
\end{tabular}

Abbreviations: HSV, herpes simplex virus; PCR, polymerase chain reaction; HSV-I, HSV type I; HSV-2, HSV type 2; Neg, negative; Pos, positive.

with increasing frequency, is practically superfluous, since the sensitivity and/or specificity can significantly be reduced. ${ }^{59}$ In conclusion, clinical decisions for antiviral therapy of HSV infections should principally not be taken on the basis of HSV IgM serologic results alone.

\section{Antiviral treatment Standard antiviral therapy}

Acyclovir, valacyclovir, and famciclovir are available for standard antiviral treatment of genital herpes (Table 4). All drugs are acyclic nucleoside analogs ${ }^{63}$ and their specific antiviral activity is based on one key enzyme of HSV-1 and HSV-2, the thymidine kinase, that converts the antiviral compounds to their monophosphates. Catalyzed by cellular enzymes, the monophosphates of nucleoside analogs are further phosphorylated to diphosphates and the active triphosphates that inhibit and fix the viral DNA polymerases, an essential enzyme for HSV-1 and HSV-2 replication. The triphosphates may also be incorporated into the growing DNA chain as "false" substrate, leading to an inhibition of viral DNA synthesis. In the case of acyclovir/valacyclovir, this is caused by the absence of the hydroxy group in $3^{\prime}$ position essential for further linking. Other nucleoside analogs such as penciclovir arising from famciclovir can be incorporated into the growing DNA chain.

Acyclovir ${ }^{63}$ is used as first-line antiviral drug for the treatment of HSV infections including genital herpes. However, a disadvantage is that acyclovir has a low oral bioavailability of $\sim 15 \%-30 \%$. Diseases of skin and mucous membranes in immunocompetent persons, which also includes genital herpes, are treated with oral acyclovir, but during severe HSV infections, in particular among immunocompromised patients, the drug has to be used intravenously (iv). In genital herpes, the dosage depends on the status of infection, immunocompetency, and pregnancy. If there are more than four to five recurrences of genital herpes per year, a suppressive antiviral therapy may be considered. ${ }^{62,64}$ Data from different randomized clinical trials ${ }^{65}$ and Cochrane review ${ }^{66}$ have shown especially the efficacy of acyclovir during pregnancy in suppression of genital herpes. The topical use of acyclovir is only recommended for the treatment of labial herpes or herpetic keratoconjunctivitis and exclusively in mild cases of genital herpes (Table 4). Acyclovir is not officially licensed for the antiviral therapy during pregnancy, and administration should be especially avoided in pregnant women before the end of the 14th gestational week. ${ }^{44}$ However, results from the manufacturer's pregnancy registries ${ }^{67}$ and a Danish population-based retrospective cohort study ${ }^{68}$ have not shown an increased rate of major birth defects after oral administration of acyclovir and its topical use. Nevertheless, patients should be informed about the limited data, especially during early pregnancy, and consent should be obtained before the drug is used. Following topical application, systemic absorption of acyclovir is minimal. ${ }^{69}$ The iv administration 
Table 4 Antiviral treatment of genital herpes

\begin{tabular}{|c|c|c|c|}
\hline $\begin{array}{l}\text { Disease/kind of } \\
\text { therapy }\end{array}$ & Acyclovir & Valacyclovir & Famciclovir \\
\hline Primary genital herpes & $\begin{array}{l}3 \times 400 \mathrm{mg} \text { orally per day for } 7-10 \text { days } \\
5 \times 200 \mathrm{mg} \text { orally per day for } 7-10 \text { days }\end{array}$ & $2 \times 500 \mathrm{mg}$ orally per day for $7-10$ days & $3 \times 250 \mathrm{mg}$ orally per day for $7-10$ days \\
\hline $\begin{array}{l}\text { Severe cases of primary } \\
\text { genital herpes }\end{array}$ & $\begin{array}{l}3 \times 5 \mathrm{mg} / \mathrm{kg} \text { body weight } \\
\text { intravenously for } 5-7 \text { days, under } \\
\text { immunosuppression for } 10 \text { days }\end{array}$ & & \\
\hline $\begin{array}{l}\text { Primary genital herpes in } \\
\text { pregnant women }\end{array}$ & $5 \times 200 \mathrm{mg}$ orally per day for 10 days & & \\
\hline Recurrent genital & $2 \times 800 \mathrm{mg}$ orally for 5 days & $2 \times 500 \mathrm{mg}$ orally for 3 days & $2 \times 125 \mathrm{mg}$ orally for 5 days \\
\hline $\begin{array}{l}\text { herpes }(<5 \text { recurrences } \\
\text { per year) }{ }^{b}\end{array}$ & $\begin{array}{l}3 \times 400 \mathrm{mg} \text { orally for } 5 \text { days } \\
3 \times 800 \mathrm{mg} \text { orally for } 2 \text { days }\end{array}$ & $\mathrm{I} \times \mathrm{I}, 000 \mathrm{mg}$ orally for 5 days & $2 \times 1,000 \mathrm{mg}$ orally for I day \\
\hline $\begin{array}{l}\text { Recurrent genital herpes } \\
\text { in pregnant women } \\
\text { Preventive therapy } \\
\text { before delivery }\end{array}$ & $\begin{array}{l}3 \times 400 \mathrm{mg} \text { orally from } 36 \text { th gestational } \\
\text { week until delivery } \\
2 \times 400 \mathrm{mg} \text { orally for maximally } \\
6 \text { months }\end{array}$ & $\begin{array}{l}2 \times 250 \mathrm{mg} \text { orally for } 3 \text { days from } 36 \text { th } \\
\text { gestational week until delivery }\end{array}$ & \\
\hline $\begin{array}{l}\text { Suppressive therapy } \\
(\geq 5 \text { recurrences } \\
\text { per year) }\end{array}$ & $\begin{array}{l}2 \times 400 \mathrm{mg} \text { orally for maximally } \\
6 \text { months } \\
4 \times 200 \mathrm{mg} \text { orally for maximally } \\
6 \text { months }\end{array}$ & $\begin{array}{l}1 \times 500 \mathrm{mg} \text { orally for maximally } \\
6 \text { months }\end{array}$ & $\begin{array}{l}2 \times 250 \mathrm{mg} \text { orally for maximally } \\
6 \text { months }\end{array}$ \\
\hline
\end{tabular}

Notes: acyclovir is not approved during pregnancy (off-label use). Administration should be especially avoided before the end of I4th gestational week. 'ln mild cases, acyclovir or foscarnet sodium may be administrated topically, but this is not sufficient especially during pregnancy. For more information, see Gupta et al, ${ }^{34}$ Centers for Disease Control and Prevention ${ }^{51}$ and German STI-Society. ${ }^{62}$

of acyclovir is occasionally accompanied by side effects of the CNS, and oral administration of acyclovir can lead to gastrointestinal symptoms. Combining acyclovir with drugs toxic to the kidney should be avoided. If acyclovir is used iv, the laboratory parameters of kidney and liver metabolisms should be monitored.

Valacyclovir, ${ }^{63}$ an L-valyl ester prodrug of acyclovir, is administered orally. The drug is converted into acyclovir, catalyzed by the hepatic valacyclovir hydrolase. Since the oral bioavailability of valacyclovir is $54 \%$, the considerably higher acyclovir concentrations than after the oral use of acyclovir result in longer dosing intervals and a higher compliance of valacyclovir. Valacyclovir is used as first-line antiviral drug for the therapy of genital herpes in immunocompetent adults. Comparable to acyclovir, data support the efficacy of valacyclovir during pregnancy in the suppression of recurrent genital herpes. ${ }^{65,66}$ Valacyclovir is not approved for antiviral treatment in children and adolescents, since safety and effectiveness have not been established especially in children $<12$ years of age. ${ }^{70}$ Valacyclovir is also not licensed for use in pregnant women. Although available data are reassuring as to the safety of valacyclovir during pregnancy, ${ }^{68}$ there is substantially less experience than with acyclovir. Side effects after the use of valacyclovir correspond widely to those after oral administration of acyclovir.

Famciclovir $^{63}$ is the inactive double diacetyl precursor of the acyclic nucleoside analog penciclovir, a highly active antiherpesvirus agent, deriving from ganciclovir. Penciclovir has a very low oral bioavailability and can only be used for topical antiviral therapy of local HSV infections, but it arises after oral administration of famciclovir by the separation of ester groups in the gastrointestinal tract. The oral bioavailability of famciclovir is calculated as $77 \%$. It has also been accepted as first-line option for antiviral therapy of genital herpes. The higher stability of triphosphate of penciclovir compared to that of acyclovir might result in a prolonged antiviral efficacy. ${ }^{71}$ Similar to valacyclovir, famciclovir is not licensed for use in children and adolescents, immunosuppressed patients under the age of 25 years, and in pregnant women. There is quite limited information on the safety of famciclovir during pregnancy. Thus, it should not be considered the medication of choice for antiviral therapy of HSV infections in pregnant women. ${ }^{72}$ The most common side effects of famciclovir are headache, nausea, and mental confusion.

\section{Other antiviral therapeutic options}

Especially in immunocompromised patients, genital herpes can be related to resistance to acyclovir/valacyclovir and cross-resistance to famciclovir after prolonged antiviral treatment. The prevalence of acyclovir-resistant HSV-2 strains has been reported in up to $5 \%$ of HIV-positive patients. ${ }^{73,74}$ In these cases, the pyrophosphate analog foscarnet (trisodium phosphonoformate) is recommended for alternative antiviral treatment at a dose of $3 \times 40(-80) \mathrm{mg} / \mathrm{kg}$ body weight iv until clinical resolution. ${ }^{51}$ Additionally, suspected resistance should be verified by genotypic and/or phenotypic 
resistance testing. Foscarnet is known to inhibit the essential DNA polymerases of several DNA as well as RNA viruses and does not have to be metabolized for the expression of antiviral activity by the prevention of the pyrophosphate exchange. Therefore, it is also active against acyclovir-/ valacyclovir-/famciclovir-resistant HSV strains. Because of the high cytotoxicity, foscarnet is known to induce significant side effects such as abnormalities in the function of liver and ulcers of the urogenital mucous membranes. Since the antiviral therapy with foscarnet has to be carried out under inpatient conditions, the administration of the nucleotide analog cidofovir (off-label use, $5 \mathrm{mg} / \mathrm{kg}$ body weight once weekly or later every 2 weeks iv until clinical resolution), ${ }^{75}$ licensed for the antiviral therapy of cytomegalovirus retinitis in patients with AIDS, may be a further option. The topical use of $1 \%$ foscarnet cream or $1 \%$ cidofovir gel has been described to lead to significant healing of genital herpes in HIV-positive people with acyclovir-resistant HSV. ${ }^{75}$

In future, novel antiviral drugs belonging to the so-called helicase-primase inhibitors may improve significantly the antiviral treatment of genital herpes. It has been assumed that these non-nucleosidic inhibitors bind to the helicase-primase complex, that is essential for virus replication, and inhibit the viral DNA synthesis. Several orally administered drugs have promising anti-HSV activity as well as preclinical profiles of safety and pharmacokinetics. Amenamivir (ASP2151) has been demonstrated to be safe and effective in treating genital herpetic lesions in animal studies and clinical trials. ${ }^{76}$ In Phase II trials, the drug pritelivir (BAY 57-1293, AIC316) showed a significant effect in reducing asymptomatic genital shedding of HSV-2 as well as the herpetic lesions in individuals with genital herpes. ${ }^{77}$ Both drugs seem to be potentially useful for the treatment of infections caused by acyclovir-resistant HSV-1 and HSV-2 strains without significant side effects. ${ }^{78}$

The use of microbicides formulated in various delivery systems, for example, gels, creams, or lotions, may help to prevent sexually transmitted diseases such as genital herpes caused by transmission during sexual activities. The best investigated drug is tenofovir, a nucleoside analog reverse transcriptase inhibitor that is primarily used to prevent and treat the HIV infection. Recently, it has been shown that the vaginal application of tenofovir gel 12 hours before sexual intercourse reduces the acquisition of HSV-2 among HSV2-negative women. ${ }^{79}$ Further studies in women with symptomatic genital HSV-2 infection revealed that neither oral nor vaginal administration of tenofovir results in substantial decrease of viral shedding or symptomatic lesions. ${ }^{80}$ It was concluded from these studies that periodical intravaginal application of tenofovir gel does not have the potential as a first-line option for HSV prevention, but it can increase the range of options for the prevention of genital herpes. A further promising candidate of microbicides effective against HSV after vaginal application is VivaGel ${ }^{\mathrm{TM}}$ that is, however, not yet commercially available. For the active ingredient SPL7013, a dendrimer produced by nanotechnology, anti-HIV and antiHSV activity has been shown in vitro, in animal models, and in Phase I clinical trials among women. ${ }^{81,82}$

\section{Resistance testing}

An antiviral treatment failure caused by resistance to acyclovir, valacyclovir, or famciclovir can most likely be presumed in the absence of clinical improvements after the application of antiviral medication for at least 10 days. ${ }^{83}$ This means that it is a clinical treatment failure to give rise to resistant HSV strains. Therefore, phenotypic and/or genotypic resistance testing should be carried out. Could any resistance to acyclovir/valacyclovir, almost always combined with cross-resistance to famciclovir, be confirmed, an alternative antiviral therapy using foscarnet is recommended. Since especially the testing of resistance phenotype is time-consuming and requires at least 7-10 days, one should not wait for the laboratory results when the clinical resistance is pronounced.

For phenotypic resistance testing, plaque reduction or cytopathic effect inhibition assays, dye uptake methods, and DNA hybridization tests have mainly been described ${ }^{84}$ The plaque reduction or cytopathic effect inhibition assays have been used most frequently. Susceptibility of HSV isolates to antiviral drugs can be assessed on the basis of virus-specific morphological cell changes, the so-called cytopathic changes. It is possible to facilitate and objectify the test evaluation by means of cell proliferation assays such as the tetrazolium reduction test. ${ }^{85}$ Using these assays, the amount of living cells and the concentrations of antiviral drugs inducing 50\% inhibition of viral replication can be estimated spectrophotometrically. Due to the use of different cell cultures, there is no international standardization of the cutoff value for any resistance to date. Therefore, it is necessary that susceptible HSV-1 or HSV-2 reference strains have to be included into each test approach as sensitive controls. It is an established practice to consider HSV isolates as resistant to acyclovir (valacyclovir), penciclovir (famciclovir), and cidofovir if the $50 \%$ effective/inhibitory concentration is three to five times higher than that of the susceptible reference strain. ${ }^{86,87}$ To assess a rarely observed resistance to foscarnet, the corresponding values should be estimated $>330 \mu \mathrm{M} .{ }^{88}$ Since phenotypic resistance testing allows a clear interpretation 
of results, this method has been accepted as gold standard for HSV resistance testing till now. However, the methods require a high expenditure of time and material, and they are currently not standardized. In the laboratory, resistance phenotype can only be tested if there is a high amount of viable virus obtained from vesicle fluids or mucocutaneous swabs and grown in cell culture.

For genotyping resistance testing of HSV, the viral thymidine kinase and DNA polymerase genes are amplified and sequenced. ${ }^{84}$ To identify nonsynonymous mutations, sequence data must be interpreted in comparison to the published sequences of susceptible reference strains provided in the GenBank (eg, HSV-1 strain 17 accession no X14112 and HSV-2 strain HG 52 accession no Z86099.2). The PCR with modified primers has been used occasionally for rapid identification of special well-known mutations. Frameshift mutations, additional stop codons, as well as well-known nonsynonymous nucleotide substitutions in particular within conserved or active gene regions can be interpreted with a very high level of probability as related to resistance. The interpretation of amino acid substitutions outside of conserved or functionally essential gene centers requires the access to databases in which all mutations within the thymidine kinase and DNA polymerase genes well known from the literature are described. ${ }^{84}$ Till now, the most reliable method to assess the significance of nonsynonymous mutations for resistance of HSV-1 and HSV-2 is the alignment of the resistance phenotype and genotype of viable virus strains. For analysis of resistance genotype, a limiting effect may have the restricted amount of viral DNA, if no viable virus strains are available. In addition, the interpretation of sequence data may be difficult when mixtures of viral mutants and wild-type strains are detected in patient samples. ${ }^{89}$ However, a crucial advantage of genotyping is a significantly shorter duration ( $\sim 2$ days depending on the viral load) compared to phenotyping and possibility to test samples without the need to grow the virus in cell culture which is of significant clinical relevance for the antiviral therapeutic decision.

\section{Prevention}

\section{Common procedures}

For counseling couples, HSV type-specific serology is a useful tool to identify HSV-2 carriers who can transmit the virus to their sexual partner. If the partner of HSV-2-positive persons has no detectable antibody, the use of condoms for safer sex should be recommended. ${ }^{90}$ In case of symptomatic genital herpes lesions or prodromal symptoms, people should be counseled to abstain from sexual intercourse. ${ }^{91}$
Both partners should be informed about their HSV status and the possible consequences of genital herpes as well as asymptomatic shedding including the impact on pregnancy. Especially in young women with high physical and mental stresses, psychotherapeutic support can help to reduce the frequency of recurrent genital episodes.

\section{Vaccination}

Despite any attempts, neither therapeutic nor prophylactic vaccines are currently available for treatment and prevention of genital herpes. The primary goal of therapeutic vaccines is to reduce HSV recurrences and asymptomatic shedding in patients with existing latent HSV infection. By contrast, prophylactic vaccines aim at prevention of acute disease and latent infection in HSV-seronegative people. To date, many therapeutic and prophylactic vaccine candidates have been tested especially in mouse and guinea pig vaginal infection models. ${ }^{92}$ However, the animal models have several disadvantages, and the results can only be transferred partially to humans. Nevertheless, promising results have been obtained by combination of the $\mathrm{CD}^{+} \mathrm{T}$-cell immunogen ICP4 with the HSV-2 gD to induce potent humoral and cellular immune responses. ${ }^{93}$ Recently, a novel adjuvanted HSV-2 subunit vaccine consisting of the recombinantly expressed viral proteins gD2, UL19, and UL25 has been tested successfully in animal models as a promising vaccine candidate for the treatment and prevention of genital herpes by vaccination. ${ }^{94}$

In humans, a therapeutic vaccine has to induce immune response that is more effective than those after recurrent HSV infection. Different results were achieved in randomized, placebo-controlled clinical trials in men and women with more than four recurrences of genital herpes per year using gD2 and combined gB2/gD2 HSV-2 subunit vaccines with MPL-alum or MF59 adjuvants. ${ }^{95,96}$ While the use of gD2 with MLP and alum led to fewer virologically confirmed HSV-2 recurrences, ${ }^{95}$ gB2/gD2 plus MF59 only resulted in a reduced severity of symptoms, time of healing, and duration to develop new lesions but not in a reduction of recurrences. ${ }^{96}$ Similarly, modified live attenuated deletion mutant viruses have been evaluated with varying degrees of success in randomized placebo-controlled studies. ${ }^{97,98}$ Using a live attenuated HSV-2 with a deletion within the large subunit of ribonucleotide reductase to compromise the ability to establish viral latency, recurrent HSV-2 genital diseases were prevented in one-third of 32 patients of both sexes with a minimum of five recurrences per year initially. ${ }^{97}$ In the second study, the use of a replication-incompetent HSV-2 vaccine lacking the glycoprotein $\mathrm{H}$ gene had no efficacy on 
the number of HSV-2 recurrences and genital virus shedding in men and women. ${ }^{98}$ Clinical trials for prophylactic HSV-2 vaccines have included gD2/gB2 subunit vaccines with MF-59 adjuvant as well as gD2 subunit vaccines with MLP-alum adjuvant. While the gD2/gB2 subunit vaccine did not induce any seroconversion in HSV-2-negative partners, ${ }^{99,100}$ different studies using gD2 subunit vaccines showed (i) efficacy in HSV-1- and HSV-2-seronegative women but not in HSV-1-seropositive women and men ${ }^{101}$ and (ii) efficacy against genital infection caused by HSV-1 but not HSV-2 in HSV-1- and HSV-2-seronegative women. ${ }^{102}$ Even though there is currently no licensed therapeutic or prophylactic vaccine against genital herpes in humans, preliminary studies have provided promising insights into mechanisms for treatment and prevention of genital herpes by vaccination. Virusspecific antibodies are most likely the dominant mediators to protect against primary infection, while cellular immunity probably triggers the prevention of recurrences. ${ }^{92,103}$

\section{Conclusion}

The genital herpes is a global medical problem, and the medical management of affected patients is often unsatisfactory. Considering the present possibilities of laboratory diagnosis, antiviral therapy, and prevention by suppressive antiviral treatment, the management of patients including their counseling may significantly be improved. Nevertheless, further effective and well-tolerated drugs for antiviral treatment, especially in case of acyclovir resistance, are required, and even more vaccines must be provided for the effective prevention of primary and recurrent genital herpes infections. To date, the data about the use of the novel helicase-primase inhibitors as well as prophylactic and therapeutic HSV vaccines have provided promising results.

\section{Disclosure}

The author reports no conflicts of interest in this work.

\section{References}

1. King AM, Adams MJ, Carstens EB, Lefcowitz EJ. Virus Taxonomy. Ninth Report of the International Committee on Taxonomy of Viruses. San Diego, CA: Elsevier Academic Press; 2012:99-124.

2. Kukhanova MK, Korovina AN, Kochetkov SN. Human herpes simplex virus: life cycle and development of inhibitors. Biochemistry (Mosc). 2014;79:1635-1653.

3. Ward PL, Roizman B. Herpes simplex genes: the blueprint of successful human pathogen. Trends Genet. 1994;10:267-274.

4. Bergström T, Trybala E. Antigenic differences between HSV-1 and HSV-2 glycoproteins and their importance for type-specific serology. Intervirology. 1996;39:176-184.

5. Scheper T, Saschenbrecker S, Steinhagen K, et al. The glycoproteins $\mathrm{C}$ and $\mathrm{G}$ are equivalent target antigens for the determination of herpes simplex virus type 1-specific antibodies. J Virol Methods. 2010;166:42-47.
6. Koelle DM, Wald A. Herpes simplex virus: the importance of asymptomatic shedding. J Antimicrob Chemother. 2000;45 Suppl T3:1-8.

7. Smith JS, Robinson NJ. Age-specific prevalence of infection with herpes simplex virus types 2 and 1: a global review. $J$ Infect Dis. 2002;186 Supp1 1:S3-S28.

8. Sauerbrei A, Schmitt S, Scheper T, et al. Seroprevalence of herpes simplex virus type 1 and type 2 in Thuringia, Germany, 1999 to 2006. Euro Surveill. 2011;16(44). pii: 20005.

9. Wutzler P, Doerr HW, Färber I, et al. Seroprevalence of herpes simplex virus type 1 and type 2 in selected German populations-relevance for the incidence of genital herpes. J Med Virol. 2000;61:201-207.

10. Peña KC, Adelson ME, Mordechai E, Blaho JA. Genital herpes simplex virus type 1 in women: detection in cervicovaginal specimens from gynecological practices in the United States. J Clin Microbiol. 2010;48:150-153.

11. Langenberg AG, Corey L, Ashley RL, Leong WP, Straus SE. A prospective study of new infections with herpes simplex virus type 1 and type 2 . Chirion HSV Vaccine Study Group. N Engl J Med. 1999;341:1432-1438.

12. Vyse AJ, Gay NJ, Slomka MJ, et al. The burden of infection with HSV-1 and HSV-2 in England and Wales: implications for the changing epidemiology of genital herpes. Sex Transm Infect. 2000;76:183-187.

13. Morrow RA, Brown ZA. Common use of inaccurate antibody assays to identify infection status with herpes simplex virus type 2 . Am J Obstet Gynecol. 2005;193:361-362.

14. Freeman EE, Weiss HA, Glynn JR, et al. Herpes simplex virus 2 infection increases HIV acquisition in men and women: systematic review and meta-analysis of longitudinal studies. AIDS. 2006;20:73-83.

15. Xu F, Lee FK, Morrow RA, et al. Seroprevalence of herpes simplex virus type 1 in children in the United States. J Pediatr. 2007;151:374-377.

16. Puhakka L, Sarvikivi E, Lappalainen M, Surcel HM, Saxen H. Decrease in seroprevalence for herpesviruses among pregnant women in Finland: cross-sectional study of three time points 1992, 2002 and 2012. Infect Dis (Lond). 2015;14:1-5.

17. Roberts CM, Pfister JR, Spear SJ. Increasing proportion of herpes simplex virus type 1 as a cause of genital herpes infection in college students. Sex Transm Dis. 2003;30:797-800.

18. Lafferty WE, Coombs RW, Benedetti J, Critchlow C, Coorey L. Recurrences after oral and genital herpes simplex virus infection. Influence of site of infection and viral type. N Engl J Med. 1987;316:1444-1449.

19. Wutzler P, Sauerbrei A. Herpes-simplex-virus, varicella-zoster-virus. In: Doerr HW, Gerlich WH, editors. Medizinische Virologie. Stuttgart: Thieme; 2010:658-665.

20. Whitley RJ, Roizman B. Herpes simplex virus infections. Lancet. 2001;357:1513-1518.

21. Gross G. Herpes-simplex-Virusinfektionen [Herpes simplex virus infections]. Hautarzt. 2004;55:818-830. German.

22. Kinchington PR, Leger AJ, Guedon JM, Hendricks RL. Herpes simplex virus and varicella zoster virus, the house guests who never leave Herpesviridae. 2012;3:5.

23. Stevens JG, Cook ML. Latent herpes simplex virus in spinal ganglia of mice. Science. 1971;173:843-845.

24. Scott DA, Coulter WA, Lamey PJ. Oral shedding of herpes simplex virus type 1: a review. J Oral Pathol Med. 1997;26:441-447.

25. Wald A, Corey L, Cone R, Hobson A, Davis G, Zeh J. Frequent genital herpes simplex virus 2 shedding in immunocompetent women. Effect of acyclovir treatment. J Clin Invest. 1997;99:1092-1097.

26. Perna JJ, Mannix ML, Rooney JF, Notkins AL, Straus SE. Reactivation of latent herpes simplex virus infection by ultraviolet light: a human model. J Am Acad Dermatol. 1987;17:473-478.

27. Rand KH, Hoon EF, Massey JK, Johnson JH. Daily stress and recurrence of genital herpes. Arch Intern Med. 1990;150:1889-1893.

28. Efstathiou S, Minson AC, Field HJ, Anderson JR, Wildy P. Detection of herpes simplex virus-specific DNA sequences in latently infected mice and in humans. JVirol. 1986;57:446-455.

29. Zwaagstra JC, Ghiasi H, Slanina SM, et al. Activity of herpes simplex virus type 1 latency-associated transcripts (LAT) promoter in neuronderived cells: evidence for neuron specificity and for a large LAT transcript. J Virol. 1990;644:5019-5028. 
30. Kennedy PG, Rovnak J, Badani H, Cohrs R. A comparison of herpes simplex virus type 1 and varicella-zoster virus latency and reactivation. J Gen Virol. 2015;96:1581-1602.

31. Wagenlehner FM, Brockmeyer NH, Discher T, Friese K, Wichelhaus TA. The presentation, diagnosis and treatment of sexually transmitted infections. Dtsch Arztebl Int. 2016;113:11-23.

32. Bernstein DI, Bellamy AR, Hook EW 3rd, et al. Epidemiology, clinical presentation, and antibody response to primary infection with herpes simplex virus type 1 and type 2 in young women. Clin Infect Dis. 2013;56:344-351.

33. Corey L, Adams HG, Brown ZA, Holmes KK. Genital herpes simplex virus infections: clinical manifestations, course, and complications. Ann Intern Med. 1983;98:958-972.

34. Gupta R, Warren T, Wald A. Genital herpes. Lancet. 2007;370:2127-2137.

35. Bennedetti J, Corey L, Ashley R. Recurrence rates in genital herpes after symptomatic first-episode infection. Ann Intern Med. 1994;121:847-854.

36. Engelberg R, Carrell D, Krantz E, Corey L, Wald A. Natural history of genital herpes simplex virus type 1 infection. Sex Transm Dis. 2003;30:174-177.

37. Dwyer DE, Cunningham AL. 10: Herpes simplex virus and varicellazoster virus infections. Med J Aust. 2002;177:267-273.

38. Hofstetter AM, Rosenthal L, Stanberry LR. Current thinking on herpes genitalis. Curr Opin Infect Dis. 2014;27:75-83.

39. Anzivino E, Fioriti D, Mischitelli M, et al. Herpes simplex virus infection in pregnancy and in neonate: status of art of epidemiology, diagnosis, therapy and prevention. Virol J. 2009;6:40.

40. Sauerbrei A, Wutzler P. Herpes simplex and varicella-zoster virus infections during pregnancy - current concepts of prevention, diagnosis and therapy. Part 1: herpes simplex virus infections. Med Microbiol Immunol. 2007;196:89-94.

41. Rudnick CM, Hoekzema GS. Neonatal herpes simplex virus infections. Am Fam Physician. 2002;6:1138-1142.

42. Corey L, Wald A. Maternal and neonatal HSV infections. $N$ Engl J Med. 2009;361:1376-1385.

43. Kohl S. Neonatal herpes simplex virus infection. Clin Perinatol. 1997;24:129-150.

44. Sauerbrei A. Herpes-simplex-Virusinfektionen [Herpes simplex virus infections]. S2k-Leitlinie Labordiagnostik schwangerschaftsrelevanter Virusinfektionen. Berlin: Springer; 2014:145-157. German.

45. Legoff J, Péré H, Bélec L. Diagnosis of genital herpes simplex virus infection in the clinical laboratory. Virol J. 2014;11:83.

46. Deutsche STI-Gesellschaft. S1-Leitlinie STI/STD - Beratung, Diagnostik und Therapie. Available from: http://www.awmf.org/uploads/ tx_szleitlinien/059-0061_S1_STI_STD-Beratung_2015-07.pdf. Accessed February 19, 2016.

47. Sauerbrei A, Eichhorn U, Hottenrott G, Wutzler P. Virological diagnosis of herpes simplex encephalitis. J Clin Virol. 2000;17:31-36.

48. Wald A, Huang ML, Carrell D, Selke S, Corey L. Polymerase chain reaction for detection of herpes simplex virus (HSV) DNA on mucosal surface: comparison with HSV isolation in cell culture. J Infect Dis. 2003;188:1345-1351.

49. Centers for Disease Control and Prevention. Diseases characterized by genital, anal, or perianal ulcers. Available from: http://www.cdc. gov/std/tg2015/genital-ulcers.htm. Accessed February 5, 2016.

50. Sauerbrei A, Eichhorn U, Schacke M, Wutzler P. Laboratory diagnosis of herpes zoster. J Clin Virol. 1999;14:31-36.

51. Centers for Disease Control and Prevention. Sexually transmitted diseases treatment guidelines. Genital HSV infections. Available from: http:// www.cdc.gov/std/tg2015/herpes.htm. Accessed February 23, 2016.

52. Swiss herpes management forum. Swiss recommendations for the management of genital herpes and herpes simplex virus infection in the neonate. Swiss Med Wkly. 2004;134:205-214.

53. Delany-Moretlwe S, Jentsch U, Weiss H, et al. Comparison of focus HerpeSelect and Kalon HSV-2 gG2 ELISA serological assays to detect herpes simplex virus type 2 antibodies in South African population. Sex Transm Infect. 2010;86:46-50.
54. Brown ZA. Case study: type-specific HSV serology and the correct diagnosis of first-episode genital herpes during pregnancy. Herpes. 2002;9:24-26.

55. Zahariadis G, Severini A. Evaluation of a novel serology algorithm to detect herpes simplex virus 1 or 2 antibodies. Sex Transm Dis. 2010;37:696-699.

56. Bentley J, Neubauer A, Sauerbrei A. Value of herpes simplex virus type-specific serology: a case report. J Clin Virol. 2012;54: 269-271.

57. Hashido M, Inouye S, Kawana T. Differentiation of primary genital herpes infections by a herpes simplex virus-specific immunoglobulin G avidity assay. J Clin Microbiol. 1997;35:1766-1768.

58. Sauerbrei A, Wutzler P. Laboratory diagnosis of central nervous system infections caused by herpesviruses. J Clin Virol. 2002;25 Suppl:45-51.

59. Liermann K, Schäfler A, Henke A, Sauerbrei A. Evaluation of commercial HSV IgG and IgM enzyme immunoassays. J Virol Methods. 2014;199:29-34

60. Page J, Taylor J, Tideman RL, et al. Is HSV serology useful for the management of first episode genital herpes? Sex Transm Infect. 2003;79;276-279.

61. Morrow R, Friedrich D. Performance of a novel test for $\operatorname{IgM}$ and $\operatorname{IgG}$ antibodies in subjects with culture-documented genital herpes simplex virus-1 or -2 infection. Clin Microbiol Infect. 2006;12:463-469.

62. German STI-Society. STI-treatment pocket guide. Available from: http://dstig.de/images/DSTIG-Flyer/Leitfaden/sti-treatment $\% 20$ pocket\%20guide_2014.2015_web.pdf. Accessed February 19, 2016.

63. De Clercq E. Selective anti-herpesvirus agents. Antivir Chem Chemother. 2013;23:93-101.

64. Le Cleach L, Trinquart L, Do G, et al. Oral antiviral therapy for prevention of genital herpes outbreaks in immunocompetent and nonpregnant patients (review). Cochrane Database Syst Rev. 2014;8:CD009036.

65. Canadian Agency for Drugs and Technologies in Health. Acyclovir versus valacyclovir for herpes virus in children and pregnant women: a review of the clinical evidence and guidelines. CADT Rapid Response Reports. 2014.

66. Hollier LM, Wendel GD. Third trimester antiviral prophylaxis for preventing maternal genital herpes simplex virus (HSV) recurrences and neonatal herpes. Cochrane Database Syst Rev. 2008;1:CD004946.

67. GlaxoSmithKline. Acyclovir and valacyclovir pregnancy registries. Available from: http://pregnancyregistry.gsk.com/acyclovir.html. Accessed February 22, 2016.

68. Pasternak B, Hviid A. Use of acyclovir, valacyclovir, and famciclovir in the first trimester of pregnancy and the risk of birth defects. JAMA. 2010;304:859-866.

69. Valeant Pharmaceuticals North America. Zovirax ${ }^{\circledR}$ (acyclovir) cream 5\% for topical use. Available from: http://www.valeant.com/Portals/25/ Pdf/PI/Zovirax\%20Cream_9386500_April\%202014.pdf. Accessed February 22, 2016.

70. GlaxoSmithKline. Product monograph Valtrex ${ }^{\circledR}$. Available from: http:// ca.gsk.com/media/593038/valtrex.pdf. Accessed February 22, 2016.

71. Simpson D, Lyseng-Williamson KA. Famciclovir: a review of its use in herpes zoster and genital and orolabial herpes. Drugs. 2006;66:2397-2416.

72. Kang SH, Chua-Gocheco A, Einarson A. Safety of antiviral medication for the treatment of herpes during pregnancy. Can Fam Physician. 2011;57:427-428.

73. Danve-Szatanek C, Aymard M, Thouvenot D, et al. Surveillance network for herpes simplex virus resistance to antiviral drugs: 3-year follow-up. J Clin Microbiol. 2004;42:242-249.

74. Reyes M, Shaik NS, Graber JM, et al. Acyclovir-resistant genital herpes among persons attending sexually transmitted disease and human immunodeficiency virus clinics. Arch Intern Med. 2003;163:76-80.

75. Patel R, Green J, Clarke E, et al. 2014 UK national guideline for the management of anogenital herpes. Int J STD AIDS. 2015;26:763-776.

76. Tyring S, Wald A, Zadeikis N, Dhadda S, Takenouchi K, Rorig R. ASP2151 for the treatment of genital herpes: a randomized, doubleblind, placebo- and valacyclovir-controlled, dose-finding study. J Infect Dis. 2012;205:1100-1110. 
77. Wald A, Corey L, Timmler B, et al. Helicase-primase inhibitor pritelivir for HSV-2 infection. N Engl J Med. 2014;370:201-210.

78. Collot M, Rouard C, Brunet C, Agut H, Boutolleau D, Burrel S. High conservation of herpes simplex virus UL5/UL52 helicase-primase complex in the era of new antiviral therapies. Antiviral Res. 2016;128:1-6.

79. Abdool Karim SS, Abdool Karim Q, Kharsany AB, et al. Tenofovir gel for the prevention of herpes simplex virus type 2 infection. $N$ Engl $J$ Med. 2015;373:530-539.

80. Bender Ignacio RA, Perti T, Magaret AS, et al. Oral and vaginal tenofovir for genital herpes simplex virus type 2 shedding in immunocompetent women: a double-blind, randomized, cross-over trial. $J$ Infect Dis. 2015;212:1949-1956.

81. Rupp R, Rosenthal SL, Stanberry LR. VivaGel ${ }^{\mathrm{TM}}$ (SPL7013 Gel): a candidate dendrimer-microbicide for the prevention of HIV and HSV infection. Int J Nanomedicine. 2007;2:561-566.

82. Price CF, Tyssen D, Sonza S, et al. SPL 7013 Gel $\left(\right.$ VivaGel $\left.^{\circledR}\right)$ retains potent HIV-1 and HSV-2 inhibitory activity following vaginal administration in humans. PLoS One. 2011;6:e24095.

83. Balfour HH Jr, Benson C, Braun J, et al. Management of acyclovirresistant herpes simplex and varicella-zoster virus infections. J Acquir Immune Defic Syndr. 1994;7:254-260.

84. Sauerbrei A, Bohn-Wippert K, Kaspar M, Krumbholz A, Karrasch M, Zell R. Database on natural polymorphisms and resistance-related non-synonymous mutations in thymidine kinase and DNA polymerase genes of herpes simplex virus type 1 and 2.J Antimicrob Chemother. 2016;71:6-16.

85. Schubert A, Gentner E, Bohn K, Schwarz M, Mertens T, Sauerbrei A. Novel single nucleotide polymorphisms of thymidine kinase and DNA polymerase genes in clinical herpes simplex virus type 1 isolates associated with different resistance phenotypes. Antiviral Res. 2014;107:16-22.

86. Morfin F, Thouvenot D. Herpes simplex virus resistance to antiviral drugs. J Clin Virol. 2003;26:29-37.

87. Schmidt S, Bohn-Wippert K, Zell R, Schlattmann P, Sauerbrei A. Sequence analysis of herpes simplex virus type 1 thymidine kinase and DNA polymerase genes from over 300 clinical isolates from 1973-2014 finds novel mutations which may be relevant for development of antiviral resistance. Antimicrob Agents Chemother. 2015;59:4938-4945.

88. Safrin S, Crumpacker C, Chatis P, et al. A controlled trial comparing foscarnet with vidarabine for acyclovir-resistant mucocutaneous herpes simplex in the acquired immunodeficiency syndrome. $N$ Engl J Med. 1991;325:551-555.

89. Nugier F, Colin JN, Aymard M, Langlois M. Occurrence and characterization of acyclovir-resistant herpes simplex virus isolates: report on a two-year sensitivity screening survey. J Med Virol. 1992;36:1-12.
90. Stanaway JD, Wald A, Martin ET, Gottlieb SL, Magaret AS. Casecrossover analysis of condom use and herpes simplex virus type 2 acquisition. Sex Transm Dis. 2012;39:388-393.

91. Gottlieb SL, Douglas JM Jr, Foster M, et al. Incidence of herpes simplex virus type 2 infection in 5 sexually transmitted disease (STD) clinics and the effect of HIV/STD risk-reduction counselling. J Infect Dis. 2004;15:1059-1067.

92. Awasthi S, Friedman M. Status of prophylactic and therapeutic genital herpes vaccines. Curr Opin Virol. 2014;6:6-12.

93. Skoberne M, Cardin R, Lee A, et al. An adjuvanted herpes simplex virus 2 subunit vaccine elicits a $\mathrm{T}$ cell response in mice and is an effective therapeutic vaccine in Guinea pigs. $J$ Virol. 2013;87: 3930-3942.

94. Odegard JM, Flynn PA, Campbell DJ, et al. A novel HSV-2 subunit vaccine induces GLA-dependent CD4 and CD8 T cell responses and protective immunity in mice and guinea pigs. Vaccine. 2016;34: 101-109.

95. Straus SE, Corey L, Burke RL, et al. Placebo-controlled trial of vaccination with recombinant glycoprotein D of herpes simplex virus type 2 for immunotherapy of genital herpes. Lancet. 1994;343:1460-1463.

96. Straus SE, Wald A, Kost RK, et al. Immunotherapy of recurrent genital herpes with recombinant herpes simplex virus type 2 glycoprotein $\mathrm{D}$ and B. Results of a placebo-controlled vaccine trial. $J$ Infect Dis. 1997;176:1129-1134.

97. Casanova G, Cancela R, Alonzo L, et al. A double-blind study of the efficacy and safety of the ICP10deltaPK vaccine against recurrent genital HSV-2 infections. Cutis. 2002;70:235-239.

98. deBruyn G, Vargas-Cortez M, Warren T, et al. A randomized controlled trial of a replication defective ( $\mathrm{gH}$ deletion) herpes simplex virus vaccine for the treatment of recurrent genital herpes among immunocompetent subjects. Vaccine. 2006;24:914-920.

99. Langenberg AG, Burke RL, Adair SF, et al. A recombinant glycoprotein vaccine for herpes simplex virus type 2 : safety and immunogenicity. Ann Intern Med. 1995;122:889-898.

100. Corey L, Langenberg AG, Ashley R, et al. Recombinant glycoprotein vaccine for the prevention of genital HSV-2 infection: two randomized controlled trials. JAMA. 1999;282:331-340.

101. Stanberry LT, Spruance SL, Cunningham AL, et al. GlycoproteinD-adjuvant vaccine to prevent genital herpes. $N$ Engl $J$ Med. 2002;347:1652-1661.

102. Belshe RB, Leone PA, Bernstein DI, et al. Efficacy results of a trial of a herpes simplex vaccine. $N$ Engl J Med. 2012;366:34-43.

103. Halford WP, Geltz J, Messer RJ, Hasenkrug KJ. Antibodies are required for complete vaccine-induced protection against herpes simplex virus 2. PLoS One. 2015;10:e0145228.
Infection and Drug Resistance

\section{Publish your work in this journal}

Infection and Drug Resistance is an international, peer-reviewed openaccess journal that focuses on the optimal treatment of infection (bacterial, fungal and viral) and the development and institution of preventive strategies to minimize the development and spread of resistance. The journal is specifically concerned with the epidemiology of antibiotic

\section{Dovepress}

resistance and the mechanisms of resistance development and diffusion in both hospitals and the community. The manuscript management system is completely online and includes a very quick and fair peerreview system, which is all easy to use. Visit http://www.dovepress.com/ testimonials.php to read real quotes from published authors. 